\title{
Seasonal and interannual variability of carbon dioxide and water balances of a grassland
}

\author{
Adrie F. G. Jacobs • Bert G. Heusinkveld • \\ Albert A. M. Holtslag
}

Received: 12 July 2006 / Accepted: 15 August 2006 / Published online: 10 March 2007

(C) Springer Science + Business Media B.V. 2007

\begin{abstract}
There is great international concern over the increase of atmospheric carbon dioxide and its effect on vegetation and climate, and vice versa. Many studies on this issue are based on climate model calculations or indirect satellite observations. In contrast we present a 12-year study (1994-2005) on the net ecosystem exchange of carbon dioxide $(N E E)$ and precipitation surplus (i.e., precipitation-evaporation) of a grassland area in the centre of the Netherlands. On basis of direct flux observations and a process-based model we study and quantify the carbon uptake via assimilation and carbon release via soil and plant respiration. It appears that nearly year-round the assimilation term dominates, which indicates an accumulation of carbon dioxide. The mean net carbon uptake for the 12-year period is about 3 tonnes $\mathrm{C}$ per hectare, but with a strong seasonal and interannual variability depending on the weather and water budget. This variability may severely hamper the accurate quantification of carbon storage by vegetation in our present climates and its projection for future climates.
\end{abstract}

\section{Introduction}

To understand the impact of increasing atmospheric carbon dioxide on our climate, we first must consider the natural reservoirs and fluxes of carbon dioxide in the earth-atmosphereocean system. So we need to consider inventories of the carbon stored in, for example, terrestrial plants and animals, carbon in the ocean, carbon in the atmosphere, and carbon in soils. Each of these reservoirs takes up and releases carbon at different rates that must be estimated to put natural as well as anthropogenic emissions into perspective (Nitschelm et al. 1997; Betts et al. 2004; Nelson et al. 2004; Wang et al. 2002).

A. F. G. Jacobs $(\bowtie) \cdot$ B. G. Heusinkveld • A. A. M. Holtslag Dept. Meteorology and Air Quality, Wageningen University, Duivendaal 2, 6701 AP Wageningen, The Netherlands e-mail: adrie.jacobs@wur.nl 
How will crop canopies as well as natural ecosystems respond to dramatic changes in the atmospheric $\mathrm{CO}_{2}$ content? This issue is a key question in the current debate over the nature of $\mathrm{CO}_{2}$-induced global change. Will plants that depend upon them for both sustenance and shelter benefit or suffer the consequences of carbon dioxide's direct plant physiological impacts? If this consequence is uncertain, is it wise to restrict large changes in the atmospheric $\mathrm{CO}_{2}$ as much as possible? To stop or limit rising concentrations of $\mathrm{CO}_{2}$ in the atmosphere, nations are actively seeking ways to increase carbon storage capacity on land. Research so far shows that forests appear to be good candidates to act as possible long-term sinks for $\mathrm{CO}_{2}$. However, since $20 \%$ of the world's land area is covered by grasslands (Hadley 1993), such landscapes are of importance for the study of $\mathrm{CO}_{2}$ uptake or release as well. Moreover, the relatively unexplored potential for grassland soils to store carbon has increased interest in the carbon cycles of these ecosystems (Van Ginkel et al. 1999).

Currently, it is suggested that grasslands demonstrate the same $\mathrm{CO}_{2}$ accumulation rates (Hu et al. 2001) as forests. If this is correct on a long-term basis, this is of great interest in light of the discussions on global warming. Unfortunately, the majority of previous direct observations of carbon exchange over grasslands have been obtained only during short-term campaigns. For example, Kim and Verma (1990), Kim et al. (1992), Verma et al. (1992) and Ham and Knapp (1998) did experiments over natural grasslands, while Meyers (2001) and Soegaard et al. (2003) worked on rangelands. Recently, a long-term experiment was started by Suyker and Verma (2001) over a native tallgrass prairie.

About $60 \%$ of agricultural land in the Netherlands consists of grasslands, where rotational grazing is the most common land use. In the Netherlands, there is great concern about the increase of atmospheric carbon dioxide and the effect of this increase on vegetation and climate, and vice versa, but there is also great concern about aridification of land areas. That is why a long-term experimental study was started in 2002 to investigate the net release or uptake of $\mathrm{CO}_{2}$ as well as the aridification of grassland areas in the Netherlands.

Until now long-term studies on net release or uptake of $\mathrm{CO}_{2}$ were only based on climate model calculations or indirect satellite observations (Nemani et al. 2003; Cox et al. 2000). In this paper, we present an 12-year study (1994-2005) on the net ecosystem exchange of carbon dioxide $(N E E)$ and precipitation surplus (i.e., precipitation-evaporation) of a grassland area in the centre of the Netherlands on the basis of direct atmospheric flux observations over a four year period and a process-based model verified with directly measured eddy flux data.

\section{Model description}

To quantify the carbon balance, we applied a so-called $A-g_{\mathrm{s}}$ model. This is a process-based model that couples the photosynthetic assimilation, $A$, to leaf stomatal conductance, $g_{\mathrm{s}}$ (Jacobs and De Bruin 1992). For four complete years (2002 until 2005), the model results were compared with direct $\mathrm{CO}_{2}$ flux measurements obtained with the eddy-covariance technique (McMillen 1988). Subsequently, we applied the validated model for 12 years of forcing data. With this model the transpiration of the plants can be estimated (Jacobs and De Bruin 1992) as well. An advantage of an $A-g_{\mathrm{s}}$ model is that the calculations are based on simple plant characteristics, for example, whether the vegetation uses the $\mathrm{C} 3$ or $\mathrm{C} 4$ metabolism, and on atmospheric variables that are measured on a routine basis at a standard meteorological observation site. 
The carbon dioxide and water vapor in- and out-flow occurs through molecular diffusion through the stomata. As a result, the net flow density of the carbon dioxide, $A_{n}\left(\mathrm{mg} \mathrm{CO}_{2}\right.$ $\left.\mathrm{m}^{-2} \mathrm{~s}^{-1}\right)$, which results from the difference between the gross assimilation rate, $A_{g}(\mathrm{mg} \mathrm{CO}$ $\left.\mathrm{m}^{-2} \mathrm{~s}^{-1}\right)$, and the dark respiration, $R_{d}\left(\mathrm{mg} \mathrm{CO} \mathrm{CO}^{-2} \mathrm{~s}^{-1}\right)$, can be described as

$$
A_{n}=A_{g}-R_{d}=g_{l, c}\left(C_{s}-C_{i}\right)
$$

Here, $C_{s}\left(\mathrm{~m}^{3} \mathrm{~m}^{-3}\right)$ is the carbon dioxide concentration at the leaf surface, $C_{i}\left(\mathrm{~m}^{3} \mathrm{~m}^{-3}\right)$ is the carbon dioxide concentration in the leaf interior, and $g_{l, c}\left(\mathrm{~m} \mathrm{~s}^{-1}\right)$ is the leaf conductance for carbon dioxide. Both $A_{g}$ and $R_{d}$ result from photochemical reactions. Typically, they vary as a function of the photosynthetically active radiation, $P A R\left(\mathrm{~W} \mathrm{~m}^{-2} \mathrm{~s}^{-1}\right)$, the leaf temperature, $T_{l}\left({ }^{\circ} \mathrm{C}\right)$, and the internal carbon dioxide concentration, $C_{i}$. Plant physiological models for $A_{g}$ and $R_{d}$ are used successfully in practice (Collatz et al. 1991; 1992), but still can be improved for controlling factors as, for example, plant water condition (Ronda et al. 2001) or plant nutrient condition (Jacobs et al. 2003a).

In laboratory experiments the internal carbon dioxide concentration is often found to be a fraction of the external carbon dioxide concentration. Under sufficient high levels of solar radiation, it appears that the ratio of the internal and external concentration is only a function of the water vapor deficit (Goudriaan et al. 1985; Jacobs 1994; Zhang and Nobel 1996) and can be expressed by (Jacobs 1994):

$$
\frac{C_{i}-\Gamma}{C_{s}-\Gamma}=f_{o}\left(1-\frac{D_{s}}{D_{o}}\right)+f_{\min } \frac{D_{s}}{D_{o}}
$$

where, $D_{s}(\mathrm{~Pa})$ is the vapor pressure deficit at plant level, $\Gamma\left(\mathrm{mg} \mathrm{m}^{-3}\right)$ is the $\mathrm{CO}_{2}$ compensation point, $f_{o}(-)$ is the maximum value of the ratio of $C_{i}$ to $C_{s}, D_{o}$ is the value of $D_{s}$ at which the stomata close, and $f_{\min }(-)$ is a minimum value of the ratio of $C_{i}$ to $C_{s}$. Because the second term on the right hand side is very small (Jacobs et al. 1992), Eq. 2a can be simplified by:

$$
\frac{C_{i}-\Gamma}{C_{s}-\Gamma}=f_{o}\left(1-\frac{D_{s}}{D_{o}}\right)
$$

Combining Eqs. 1 and $2 \mathrm{~b}$ gives a relation for the conductance to carbon dioxide at leaf level

$$
g_{l, c}=g_{\min }+\frac{a_{1} A_{g}}{\left(C_{s}-\Gamma\right)\left(1+\frac{D_{s}}{D_{*}}\right)},
$$

where $g_{\min }\left(\mathrm{m} \mathrm{s}^{-1}\right)$ is the minimum conductance, and $a_{1}$ and $D_{*}$ are empirical quantities that are both functions of $f_{o}$ and $D_{o}$ (Ronda et al. 2001). It must be noted that in Eq. 3, $g_{\text {min }}$ was added afterwards in order to account for the cuticular conductance.

The assimilation can be seriously affected by soil water stress, especially during summer time with a low water table. Here we follow a correction for water stress as suggested by Ronda et al. (2001):

$$
A_{g}=A_{g}^{*} f\left(\theta_{r}\right)
$$


where $A_{g}{ }^{*}\left(\mathrm{mg} \mathrm{CO} \mathrm{m}^{-2} \mathrm{~s}^{-1}\right)$ is the unstressed gross assimilation rate, $\theta_{r}\left(\mathrm{~m}^{3} \mathrm{~m}^{-3}\right)$ is the mean moisture content in the root zone and $f\left(\theta_{r}\right)$ a soil moisture correction function taken as:

$$
f\left(\theta_{r}\right)=2 \beta\left(\theta_{r}\right)-\beta^{2}\left(\theta_{r}\right)
$$

and

$$
\beta\left(\theta_{r}\right)=\max \left[0, \min \left(1, \frac{\theta_{r}-\theta_{W P}}{\theta_{F C}-\theta_{W P}}\right)\right]
$$

where, $\theta_{F C}\left(\mathrm{~m}^{3} \mathrm{~m}^{-3}\right)$ and $\theta_{W P}\left(\mathrm{~m}^{3} \mathrm{~m}^{-3}\right)$ are soil moisture contents at field capacity and permanent wilting point, respectively. At our site the field capacity and permanent wilting point have the numerical values of $\theta_{F C}=0.52$ and $\theta_{W P}=0.32$, respectively.

The canopy conductance to carbon dioxide, $g_{c, c}$, is found by integrating the stomatal conductance over the canopy (Ronda et al. 2001):

$$
g_{c, c}=\frac{g_{\min }}{1.6} L A I+\frac{a_{1} A_{g} L A I}{\left(C_{s}-\Gamma\right)\left(1+\frac{D_{s}}{D_{*}}\right)}\left(1-\frac{1}{K_{x} L A I}\left(E_{1}\left(y e^{-K_{x} L A I}\right)-E_{1}(y)\right)\right)
$$

Here, $L A I\left(\mathrm{~m}^{2} \mathrm{~m}^{-2}\right)$ is the one-sided leaf area index, $K_{x}(-)$ is the canopy extinction coefficient for photosynthetically active radiation, $E_{1}(-)$ is the exponential integral defined as (Abramowitz and Stegun 1965):

$$
E_{1}(z)=\int_{z}^{\infty} \frac{e^{-t^{\prime}}}{t^{\prime}} d t^{\prime}
$$

And the dimensionless parameter $y$ is given by:

$$
y=\frac{\alpha K_{x} P_{t}}{A_{g}}
$$

Here, $z(\mathrm{~m})$ stands for height, the variable $t^{\prime}$ in the exponential integral is a dummy variable and the factor 1.6 in Eq. 7 is the ratio between molecular diffusivities of water vapor and carbon dioxide in air. In Eq. $8, \alpha\left(\mathrm{mg} \mathrm{CO}_{2} \mathrm{~J}^{-1}\right)$ is the light use efficiency and $P_{t}$ $\left(\mathrm{W} \mathrm{m}^{-2}\right.$ ) is the incoming photosynthetically active radiation at the top of the canopy.

Equations 1 and 7 together with the physiological model define the relation between the net assimilation, $A_{n}$, and the crop conductance, $g_{c, c}\left(\mathrm{~s} \mathrm{~m}^{-1}\right)$ according to:

$$
A_{n}=\frac{g_{a} g_{c, c}}{g_{a}+g_{c, c}}\left(C_{a}-C_{i}\right)=\frac{g_{c, c}}{1+\frac{g_{c, c}}{g_{a}}}\left(C_{a}-C_{i}\right)
$$

where $g_{a}\left(\mathrm{~s} \mathrm{~m}^{-1}\right)$ is the aerodynamic conductance, $C_{a}$ is the ambient $\mathrm{CO}_{2}$ concentration and $C_{i}$ is the carbon dioxide concentration in the leaf interior calculated with Eq. $2 \mathrm{~b}$. Note that $A_{n}$ and $g_{c, c}$ can be computed when the leaf area index, $L A I$, and the type of plant (C3 or C4) are known in addition to the vapor pressure deficit, $D_{s}(\mathrm{~Pa})$ (here evaluated as $\left(e_{s}\left(T_{l}\right)-e\right)$, where $e(\mathrm{~Pa})$ is the vapor pressure and $e_{s}(\mathrm{~Pa})$ is the saturated vapor pressure), the temperature at leaf level, $T_{l}$, and the amount of incoming photosynthetically active radiation, $P A R$ (here evaluated as $P A R=0.5 R_{g}$ where $R_{g}$ is the incoming short wave radiation). 
The canopy conductance for water vapor, $g_{c, w}$ is closely related to the canopy conductance for carbon dioxide, $g_{c, c}$, according to:

$$
g_{c, w}=1.6 g_{c, c} .
$$

The transpiration rate of the vegetation, $L E\left(\mathrm{~W} \mathrm{~m}^{-2}\right)$, can be written as (Beljaars and Holtslag 1991):

$$
L E=\rho L \frac{\varepsilon}{p} \frac{g_{a} g_{c, w}}{g_{a}+g_{c, w}} D_{s}=\rho L g_{c, w} \frac{\varepsilon}{p} \frac{D_{s}}{1+\frac{g_{c, w}}{g_{a}}}
$$

where $\rho\left(\mathrm{kg} \mathrm{m}^{-3}\right)$ is the density of the air, $L\left(\mathrm{~J} \mathrm{~kg}^{-1}\right)$ is the latent heat of vaporization and $\varepsilon=0.622$ is the ratio of the molar masses of water vapor and dry air, and $p(\mathrm{~Pa})$ is atmospheric pressure. A more detailed description of the model can be found in Ronda et al. (2001) and Jacobs et al. (2003a). The parameter values are taken as in Ronda et al. (2001), unless stated elsewhere in the next sections.

The soil surface carbon dioxide flux is mainly caused by heterotrophic microbial decomposition and plant root respiration in grasslands (Norman et al. 1992). The soil respiration is likely to depend on soil temperature (Norman et al. 1992) and soil water content (Grammerer 1989). In this study the soil surface respiration, $R_{s}\left(\mathrm{mg} \mathrm{CO}_{2} \mathrm{~m}^{-2} \mathrm{~s}^{-1}\right)$, has been calculated with a simple Arrhenius type of expression (Lloyd and Taylor 1994):

$$
R_{S}=R_{10}(1-f(\theta)) \exp \left(\left(\frac{E_{o}}{283.15 R^{*}}\right)\left(1-\frac{283.15}{T_{s}+273.15}\right)\right)
$$

where, $R^{*}\left(\mathrm{~kJ} \mathrm{kmol}^{-1} \mathrm{~K}^{-1}\right)$ is the universal gas constant, $E_{o}\left(\mathrm{~kJ} \mathrm{kmol}^{-1}\right)$ is the activation energy, $T_{\mathrm{s}}$ is the mean soil temperature of the upper soil at $5 \mathrm{~cm}$ depth, $R_{10}$ is the respiration at $10^{\circ} \mathrm{C}$ under no water stress condition and has for our grassland the numerical value $R_{10}=$ $0.23 \mathrm{mg} \mathrm{CO} \mathrm{Cm}^{-2} \mathrm{~s}^{-1}$ (Jacobs et al. 2005) and $[1-f(\theta)]$ is the water stress correction function where:

$$
f(\theta)=C \frac{\theta_{\max }}{\theta+\theta_{\min }}
$$

in which $\theta$ is the soil moisture content, $C(=0.0016)$ is a constant, and $\theta_{\max }(=0.55)$ and $\theta_{\min }(=0.005)$ are reference soil water contents. More details about the background of Eq. 13 can be found elsewhere (Jacobs et al. 2006). The Net Ecosystem Exchange for $\mathrm{CO}_{2}$, $N E E$ ( $\mathrm{mg} \mathrm{CO}_{2} \mathrm{~m}^{-2} \mathrm{~s}^{-1}$ ), has been evaluated as the net effect of the assimilation flux, $A_{n}$, and the soil respiration flux, $R_{s}$. NEE is calculated as:

$$
N E E=A_{n}+R_{s}
$$

Keep in mind that the assimilation flux is directed towards the earth's surface, which means this is a negative flux, while the soil respiration flux is directed from the earth's surface and consequently is positive. The model time step is from 30-min data averages (see also "Experimental lay-out" below).

\section{Experimental lay-out}

The experiments were conducted at a grassland area of the Wageningen University meteorological observatory, Haarweg Station, in the centre of the Netherlands (lat. $51^{\circ} 58^{\prime} \mathrm{N}$, long. 
$5^{\circ} 38^{\prime} \mathrm{W}$, altitude $+7 \mathrm{~m}$ a.s.l.;http://www.met.wau.nl) during a four year period from 2002 until 2005. The dominating plant species in this perennial grassland were Lolium perenne and Poa trivialis. The soil at the site is predominantly a heavy clay resulting from the back-swamps of the river Rhine. This Leaf Area Index, LAI, was kept constant as good as possible and had a numerical value of $2.9 \pm 0.3$. About monthly the $L A I$ was measured by a plant analyzer (CID-Inc. model CI-110). During the growing season (1 May-1 Nov), the grass cover was mowed weekly. With a special grass height meter (Eijkelkamp, model NMI), the mean grass height was checked daily and had a mean height of $10 \mathrm{~cm}$. There is a unique relation between the grass height and the LAI (Keuning 1988). If the LAI exceeds the maximum value of 3.2 within a week, the grass was mowed more frequently. At the measurement site the mowed grass is not removed and evenly spread over the area.

A lattice tower was instrumented with an eddy-covariance system installed at a height of $4 \mathrm{~m}$. This system included a three-dimensional sonic anemometer (3D Solent Res. Gill Instruments Ltd., model A1012R2), a fine wire thermocouple (purpose-built) and an open path infrared $\mathrm{CO}_{2}$ and $\mathrm{H}_{2} \mathrm{O}$ gas analyser (IRGA) (LI-COR Inc. Lincoln Ne, model LI7500). The 3D sonic anemometer and the IRGA were placed together, at $0.05 \mathrm{~m}$ apart. It must be noted that under calm wind conditions $\left(u^{*} \leq 0.1 \mathrm{~m} \mathrm{~s}^{-1}\right)$, turbulence is suppressed and the eddy-covariances become ill-defined since these conditions are nonstationary and nonhomogeneous. Under low wind conditions the eddy-covariances were ignored and the gaps filled with either interpolated results (small gaps) or with modelled results.

In a thermometer screen an aspirated psychrometer was installed to measure the air temperature as well as the air humidity. The incoming short-wave radiation, $Q_{g}$, was measured with an aspirated pyranometer (Kipp \& Zonen, model CM11). The short-wave radiometer was used to evaluate the PAR radiation $\left(P A R=0.5 Q_{g}\right)$, needed for the model evaluations. The outgoing long-wave radiation, $Q_{L o}$, was measured with a pyrgeometer (Kipp \& Zonen, model CG 1). The outgoing long wave radiometer was used to evaluate the surface temperature $T_{\text {surf }}(\mathrm{K}), T_{\text {surf }}=\sqrt[4]{\frac{Q_{L o}}{\varepsilon \sigma}}$, where $\sigma\left(\mathrm{W} \mathrm{m}^{-2} \mathrm{~K}^{-4}\right)$ is Stefan Boltzmann's constant and $\varepsilon(-)$ is the emissivity.

Sensitive cup anemometers (purpose-built, stalling speed $0.15 \mathrm{~m} \mathrm{~s}^{-1}$ ) measured the wind speeds at 2 and $10 \mathrm{~m}$ height above the surface and a wind vane at $10 \mathrm{~m}$ indicated the wind direction. The soil temperature profile was measured by Pt-100 elements at depths 0.05 , $0.10,0.20,0.50$ and $1 \mathrm{~m}$. The soil temperature at $0.05 \mathrm{~m}$ depth was used to estimate the soil respiration term (see Eq. 12).

To estimate the mean moisture content in the root zone, a simple bucket model is applied in which the surface runoff term is neglected. This means that the water balance rules the mean water content, $\theta_{r}$, in the root zone according to (Jury et al. 1991):

$$
\theta_{r}(t+\Delta t)=\theta_{r}(t)+\frac{N-D r-E \cdot \Delta t}{z_{f} P}+\Delta S
$$

where $N$ is precipitation amount in mm within the time interval between $t$ and $t+\Delta t, D r$ is drainage, $E$ is the evapotranspiration rate in $\mathrm{mm} \mathrm{s}^{-1}$ and, $z_{f}$ is the depth of the freatic surface in $\mathrm{mm}$ and $P$ is the soil's porosity. The drainage, $D r$, in our well drained region could simply be parameterized by (Schnel 2004):

$$
D r=f_{D} N,
$$


where $f_{D}$ is the drainage factor, which is calculated by reversed modelling and has the numerical value $f_{D}=0.14$ for our area. The storage change, $\Delta S$, has been parameterized by taking (Jury et al. 1991):

$$
\Delta S=\left(\theta_{s}-\theta_{F C}\right) \frac{\Delta z_{f}}{z_{f}}
$$

where $\theta_{s}=P$ is the saturated soil moisture content.

The slow response meteorological instruments were sampled at $0.25 \mathrm{~Hz}$. The fast response sonic anemometer, the IRGA system and the fine wire thermocouple were sampled at $20.8 \mathrm{~Hz}$. At 30-min intervals, data were averaged and stored in data loggers for later processing.

The raw data of the eddy covariance system were stored on a PC and processed later, using a first order recursive digital filter with a time constant of $200 \mathrm{~s}$ (McMillen 1988). Here a moving average was subtracted from every sample to get the fluctuating value of all the measured components. A software program (Van den Hurk 1996) performed the necessary corrections, including coordinate rotation (McMillen 1986), Webb corrections (Webb et al. 1980) and frequency response corrections (Moore 1986), required for calculating the half-hour averaged flux densities. More details about the experiments and area can be found elsewhere (Jacobs et al. 2003b).

\section{Results and discussions}

To check the model performance, for all two-monthly blocks (JanFeb, MarApr, MayJun, etc.) for the four years' experimental period, the measured daily evapoptranspiration and NEE totals are compared with the calculated daily totals. Generally, it appears that the months MayJun, JulAug mostly showed the best agreement, followed by the months MarApr SepOct, and finally followed by the months NovDec and JanFeb. An example of this comparison contains Fig. 1 for three two-month blocks in 2005. The linear regressions forced through the origin and the correlation coefficients are also plotted in Fig. 1. From this result and results discussed later, we conclude that year round the model performs reasonably well to apply for the simulations. Note that $N E E$ is not as well characterized by the model as the evapotranspiration since this result is the difference between two more or less equal terms (see Eq. 14).

The courses of the modelled total annual simulated assimilation, respiration and $N E E$ absolute fluxes are contained in Fig. 2. For the experimental period the measured $N E E$ totals also have been plotted in Fig. 2. Note that the measured NEE total agree well with the simulated $N E E$ total (mean difference $<5 \%$ ). Note also that all fluxes show a slight increase with time. The linear regressions of the assimilation and respiration fluxes are provided in Fig. 2 to give an idea of the importance of this change.

From Fig. 2 it can clearly be observed that the $N E E$ is nearly always negative. Only in 2000 and 2001 was there a small net release of $\mathrm{CO}_{2}$. This means that this grassland area mostly behaves as a sink for $\mathrm{CO}_{2}$. The same net sink behaviour for carbon dioxide was found by Suyker and Verma (2001) for a native tall grass prairie in the US. In our grassland area nearly 3 tonnes carbon per hectare per year is stored if no other exchange processes take place in which the stored $\mathrm{CO}_{2}$ is transferred and released again in other gases, for example through methane. These accumulated amounts are of the same order of magnitude 

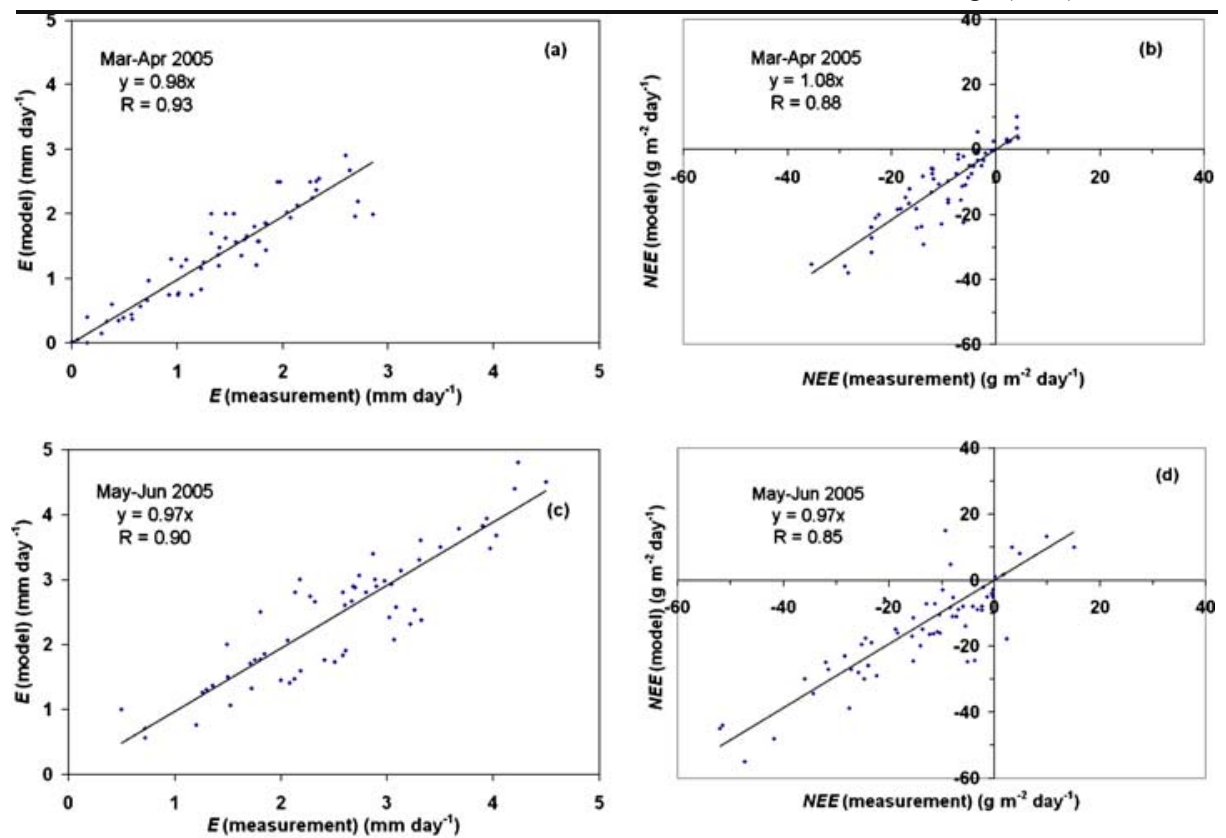

NEE (measurement) $\left(\mathrm{g} \mathrm{m}^{-2}\right.$ day $\left.^{-4}\right)$
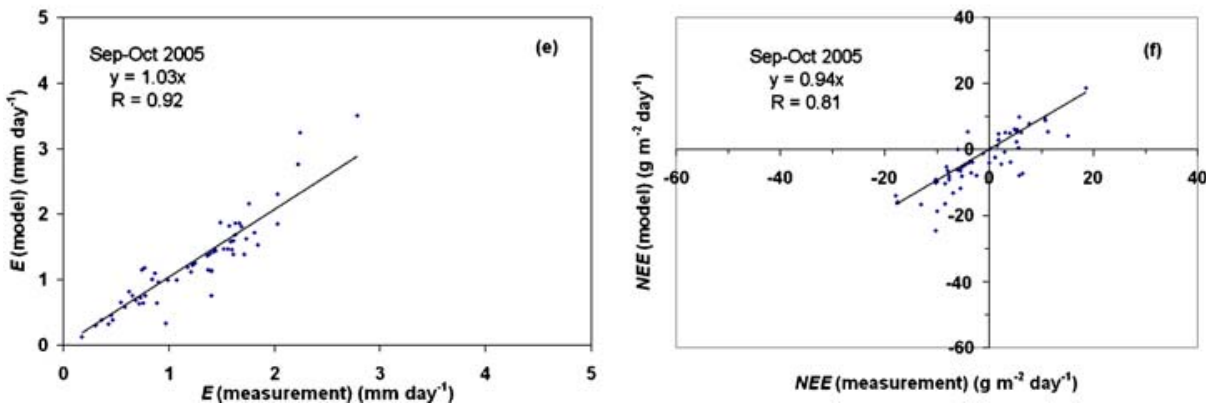

Fig. 1 A comparison of the daily measurement totals of water vapour and $N E E$ with the calculated results for three two-months blocks in 2005. The unbiased linear regressions and correlation coefficients are indicated

that is often observed in young mid-latitude forests (Valentini et al. 2000; Goulden et al. 1996; Wofsy et al. 1993).

The years 2002 and 2004 were very sunny especially during the growing season. This can clearly be inferred from the relatively large assimilation totals for these years. As mentioned earlier, the $N E E$ of the years 2000 and 2001 shows a net $\mathrm{CO}_{2}$ release. During these years, the summer months June, July and August were wet and gloomy. Probably this is the reason that these years show a net release instead of a net uptake of $\mathrm{CO}_{2}$.

Figure 3 contains the mean monthly course throughout the year, averaged over the selected 12-year period, of the modelled assimilation, modelled respiration and modelled $N E E$. From Fig. 3 we clearly infer that most of the year there is a net uptake of $\mathrm{CO}_{2}$. Only during the months October, December and January a small net release of $\mathrm{CO}_{2}$ is found. Note also that the months June and July show relatively low respiration fluxes. 


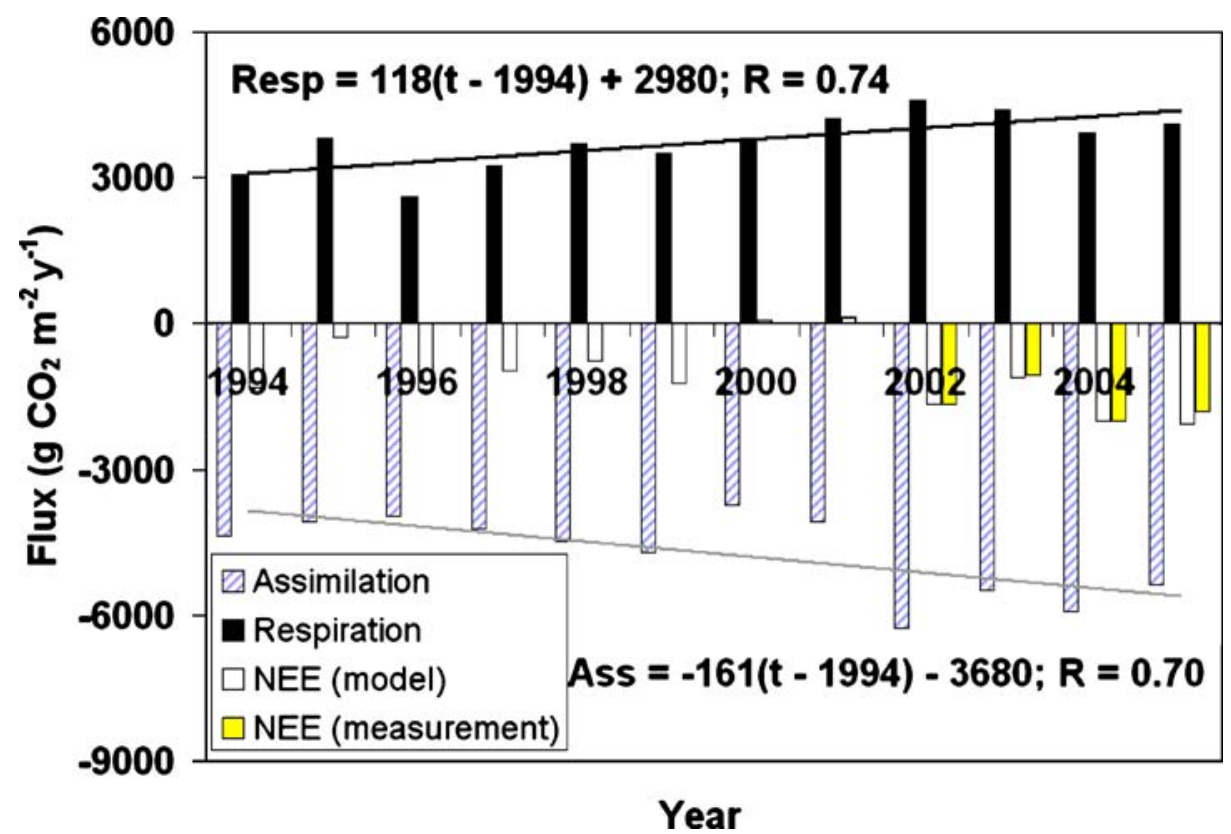

Fig. 2 The total annual fluxes of assimilation, respiration and NEE between 1994-2005. Linear regressions of the assimilation and respiration are indicated along with their correlation coefficients

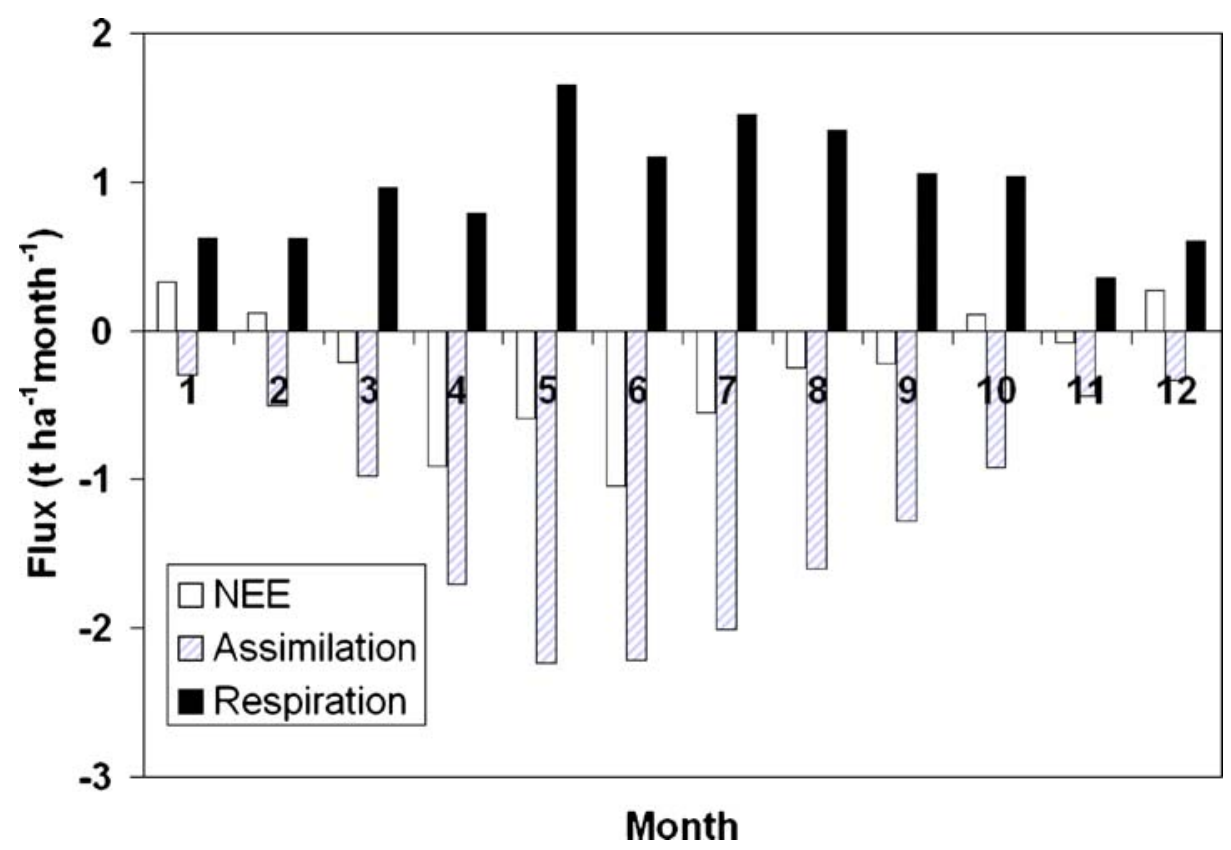

Fig. 3 The monthly averaged fluxes of the assimilation, respiration and NEE between 1994-2005 


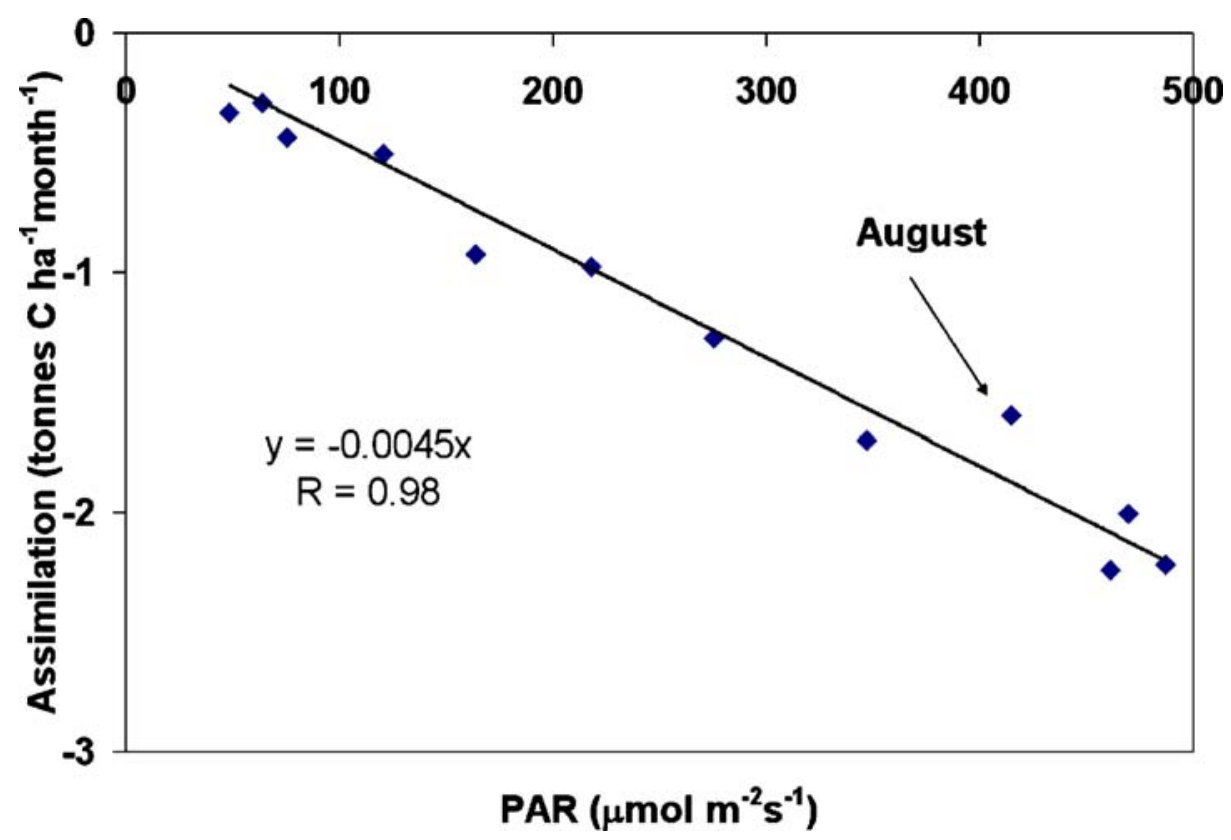

Fig. 4 The relation between the mean monthly assimilation and the PAR. The unbiased linear regression line with its correlation coefficient are indicated

During these months the soil starts to dry out which reduces considerably the respiration (see also Eq. 12).

The assimilation flux in Fig. 3 must show a clear relation with the Photosynthetically Active Radiation $(P A R)$, the part of the sun's radiation that is responsible for the plant assimilation process. A nearly linear relation between NEE and PAR must be expected since the conductance, $g_{c, c}$ (Eq. 7) is nearly linear to $P A R$. The mean monthly scattergram between $N E E$ and $P A R$, plotted in Fig. 4, does indeed reflect this relation. Only one point, the month of August (see indication in Fig. 4), deviates somewhat but not significantly from the linear regression. August is the period of the year during which soil moisture reaches its lowest values. This causes considerable plant water stress, which reduces the assimilation flux (see Eq. 5). An illustration of the behaviour of the mean root zone soil moisture content throughout the year is given in Fig. 5. In Fig. 5, the courses of the freatic surface and precipitation regime are plotted along with mean soil moisture content (Eq. 15) for 2003. Figure 6 clearly demonstrates the depression in the mean soil moisture content during the month of August (1 August = Doy 213).

In Fig. 6 the annual amounts of incoming PAR radiation are depicted along with the annual mean soil and air temperatures. From the results of Fig. 6 we can infer that these annual values do not show much variation. During the selected 12-year period, the mean annual $P A R$ radiation was $8400 \cdot 10^{6} \mu \mathrm{mol} \mathrm{m} \mathrm{m}^{-2}$, with a standard deviation of $500 \times 10^{6} \mu \mathrm{mol} \mathrm{m}{ }^{-2}$, the mean air temperature was $10.6^{\circ} \mathrm{C}$ with a standard deviation of $0.9 \mathrm{~K}$ and the mean soil temperature was $10.3^{\circ} \mathrm{C}$ with a standard deviation of $0.7 \mathrm{~K}$. In the same period, the annual fluxes of assimilation, respiration and $N E E$ had a mean value of $-14,11$ and -3 tonnes $\mathrm{C}^{-1} \mathrm{~h}^{-1}$, respectively, (with corresponding standard deviations of 3 , 2 and 2 tonnes $\mathrm{C} \mathrm{ha}^{-1}$, respectively). These variations are relatively much larger than the variations in PAR and upper soil and air temperatures. It is interesting to note that the upper 


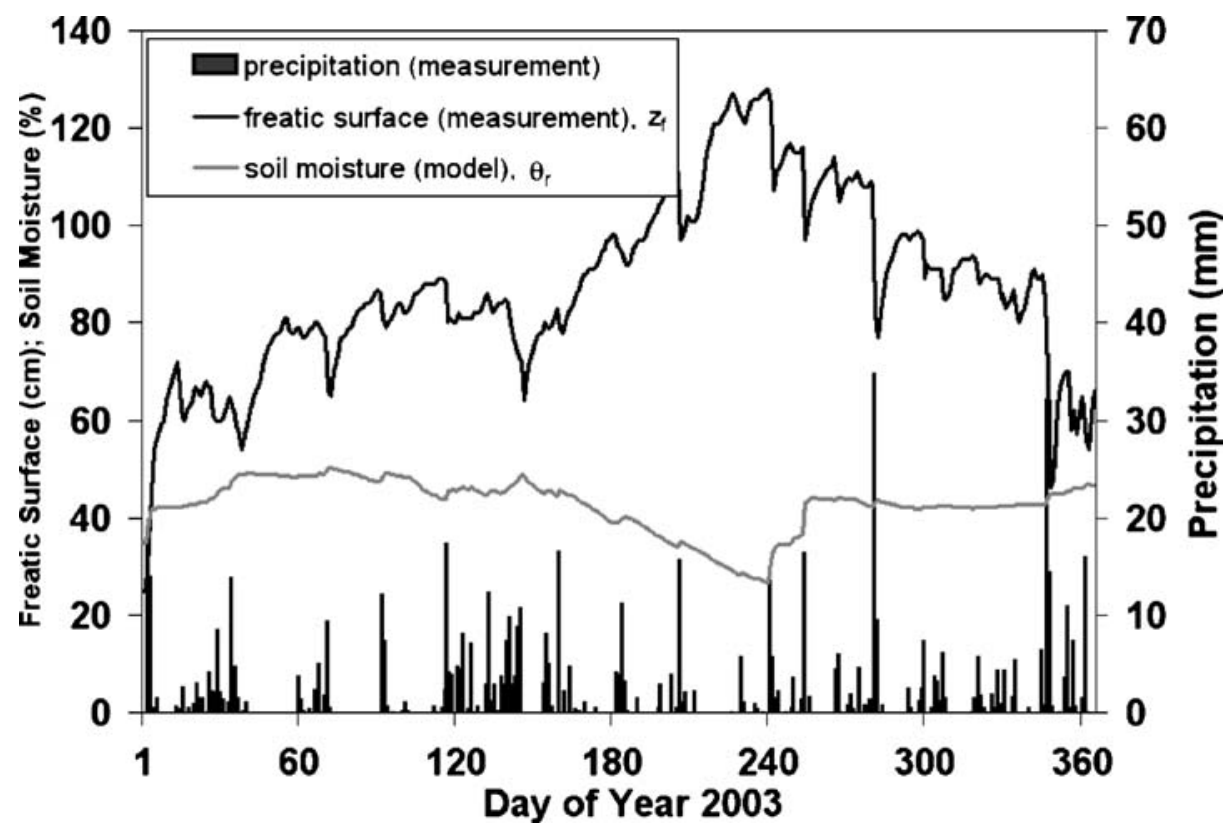

Fig. 5 The courses of the precipitation, freatic surface and the soil moisture content in 2003

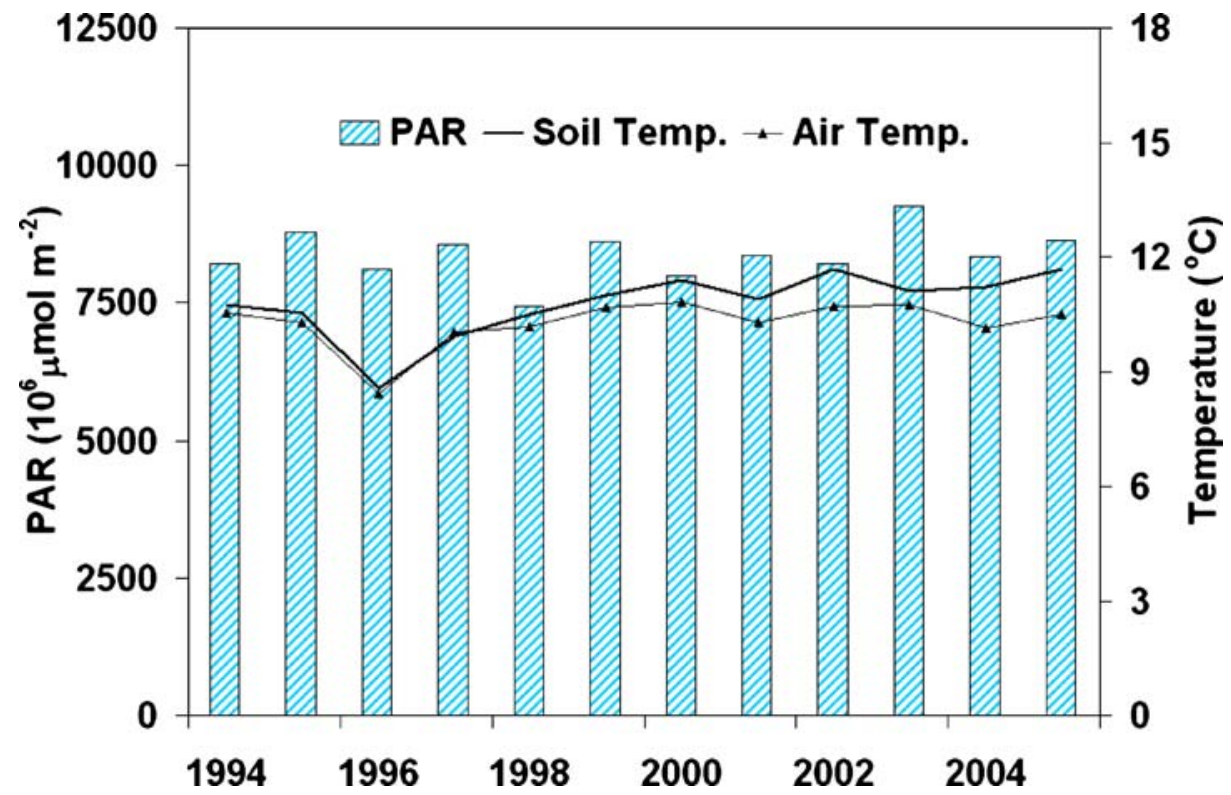

Fig. 6 The interannual course of the total $P A R$ radiation and the mean annual upper soil and air temperatures between 1994-2004 


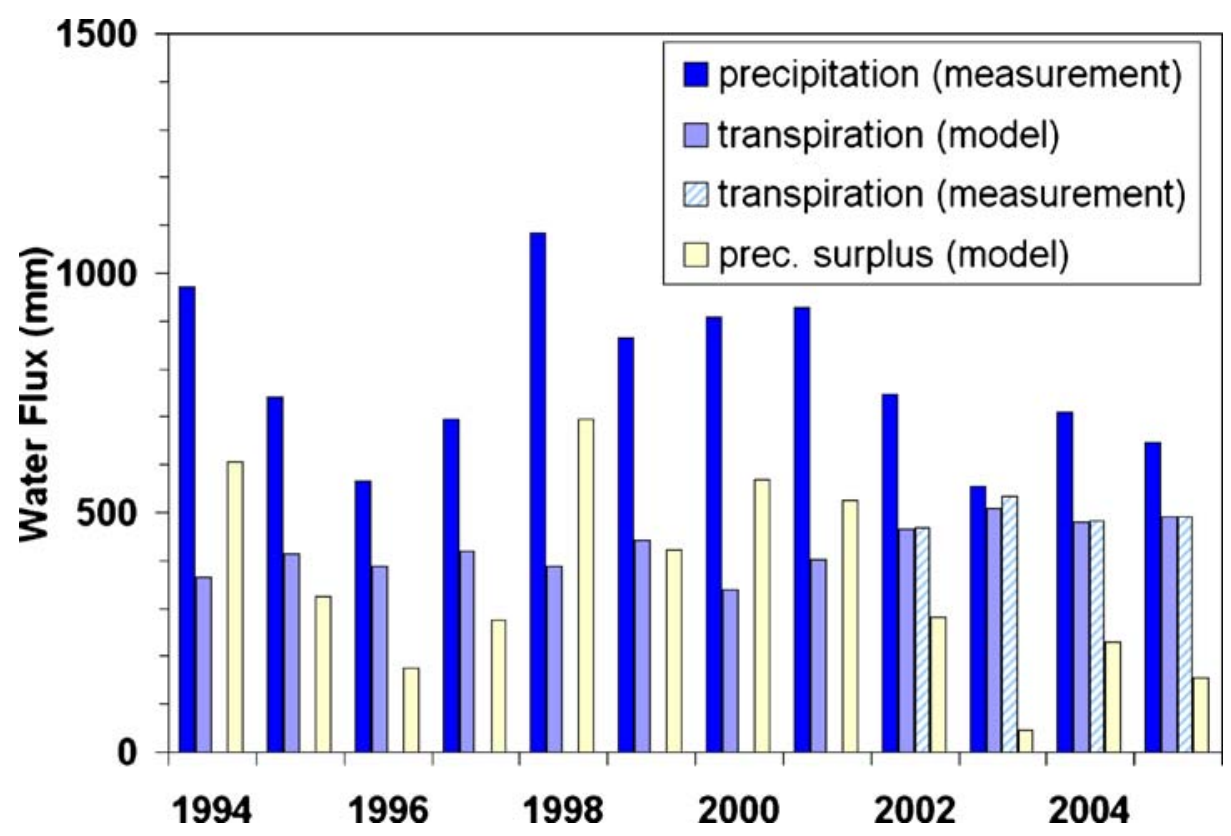

Fig. 7 The total annual water fluxes of the precipitation, transpiration and precipitation surplus between 1994-2004

soil temperature shows a small increase over time, which can be an indication of the slight increase in time of the respiration as observed in Fig. 2.

The annual courses of the most important water balance terms - precipitation, transpiration (model) and precipitation surplus (model) - are contained in Fig. 7 for the selected 12-year period. Moreover, for the last four years the measured evapotranspiration quantities have been plotted. Figure 7 shows that the measured transpiration totals agree well with the simulated totals (mean difference $<1.5 \%$ ). Note that the simulated transpiration totals do not contain the free water contribution due to dew (condensation as well as evaporation) and interception (evaporation). In another study over the same period we showed that dew is the second most important free water contribution to the water budget (Jacobs et al. 2006) and amounts about (37 \pm 8$) \mathrm{mm}^{-1}$. These dew events, however, mainly occur during calm wind conditions $\left(u^{*} \leq 1 \mathrm{~m} \mathrm{~s}^{-1}\right)$ in which the eddycovariance technique fails to measure the free water transport. That is why the evaporation contribution is not discussed here in detail.

Because the annual precipitation amount in a dry year can deviate considerably as compared to a wet year, it is clear that the evapotranspiration and the consequent precipitation surplus will show a large interannual variation as well. This effect can clearly be observed from Fig. 7, where it appears that during the selected 12-year period the precipitation surplus had a mean value of $410 \mathrm{~mm}$ with a standard deviation of $200 \mathrm{~mm}$. In comparison to the standard deviation in the mean PAR radiation and mean soil temperature, the standard deviation in the precipitation surplus is very high which means that processes depending on the precipitation surplus must also show a large standard deviation.

In Fig. 8, precipitation, evapotranspiration and precipitation surplus have been plotted throughout the year, averaged over the selected 12-year period. From Fig. 8 it can be inferred that precipitation is more or less equally distributed throughout the year. This is in 


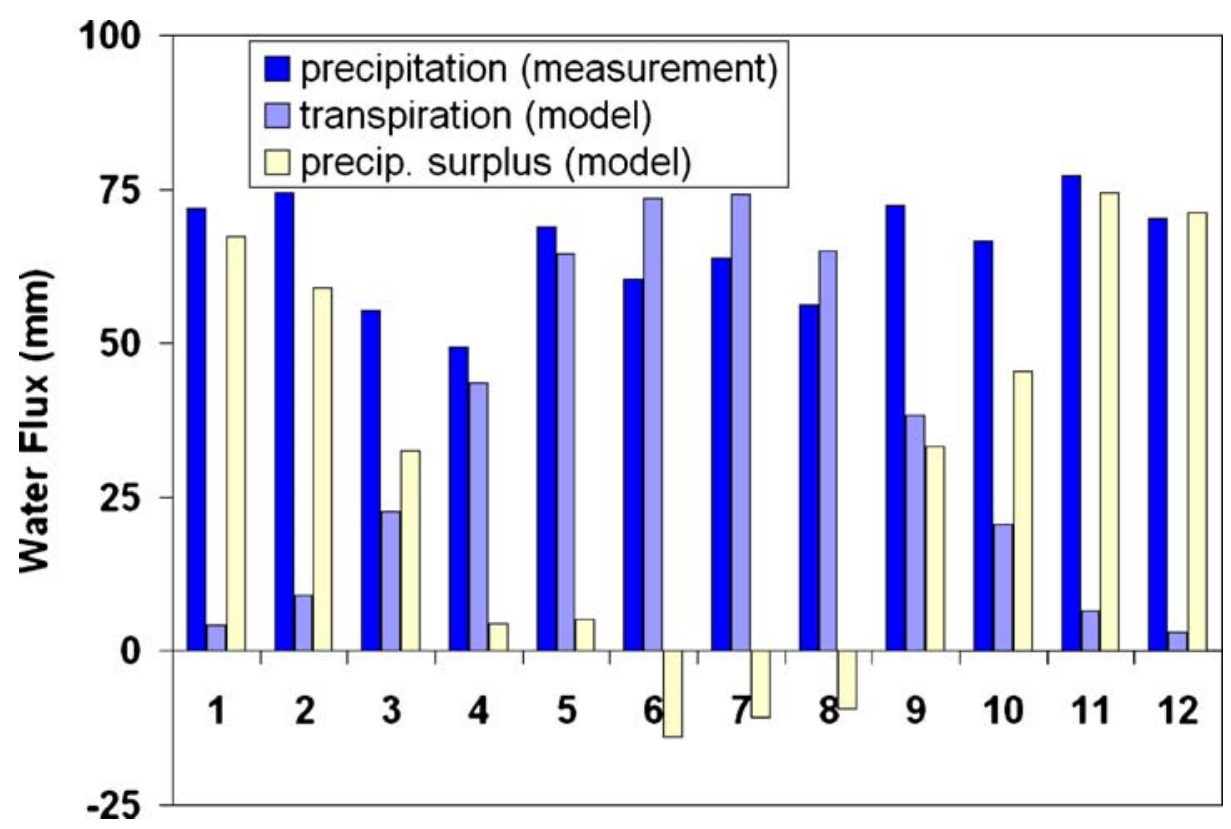

Fig. 8 The monthly averaged water fluxes of precipitation, transpiration and precipitation surplus

contrast to the course of the evapotranspiration flux, which, as must be expected in a temperate climate, is small during the winter half year and large during the summer period. Consequently, the reverse course must be observed for the precipitation surplus; large during the winter half year and small or even negative during the summer half year. During the months June, July and August there mostly exists a negative precipitation surplus where extra water will be extracted from the ground water reservoir needed for the transpiration process. This also means that particular during the summer period a shortage of water for transpiration can occur which certainly limits the transpiration process and consequently also the assimilation as well as the respiration processes (Norman et al. 1992; Jacobs et al. 2003b).

\section{Conclusions}

In this paper we quantify the surface fluxes of water vapor and net ecosystem exchange of carbon dioxide $(N E E)$ in a grassland area in the centre of the Netherlands over a period of 12 years on the basis of common meteorological weather variables during this period, direct flux observations during four years and a process-based model evaluated with the data. For the four-year period with available flux measurements it appears that the model simulated the total evapotranspiration within $1.5 \%$ and the $N E E$ within $5 \%$. Then the validated process model is applied to the 12-year period using a constant set of input data. On basis of the results we find that our grassland region in a temperate climate can serve as a sink for $\mathrm{CO}_{2}$ in the same way as young forests. The question remains, however, to what extent do other processes, such as methane transformation, play a role in the total $\mathrm{CO}_{2}$ storage in the soil. We also conclude that there is a large seasonal and interannual variation in the $N E E$. From our analysis we expect that this variation is mainly caused by strong variations in the 
incoming $P A R$ and the precipitation surplus, particularly during the summer period. As such, this strong link between the carbon balance and the two most important weather variables (incoming radiation and precipitation) may severely complicate future climate projections (Cox et al. 2000), in particular at the regional scale. We also found that during the 12-year period studied, that the increase in time of the $\mathrm{CO}_{2}$ uptake by assimilation is somewhat faster than the release of $\mathrm{CO}_{2}$ by the respiration process. This subject needs further analysis.

Acknowledgments We acknowledge the assistance of the technical staff of our Department for doing the calibrations and maintenance of the instrumentation during the experimental period. This work was partly support by the Netherlands Foundation for the Advancement of Research (NWO, Instrumentation Support).

\section{References}

Abramowitz M, Stegun IA (1965) Handbook of Mathematical Functions. Dover, Mineola, New York, p 1046

Beljaars ACM, Holtslag AAM (1991) Flux parameterization over land surfaces for atmospheric models. J Appl Meteorol 30:327-341

Betts AK, Helliker B, Berry J (2004) Coupling between $\mathrm{CO}_{2}$, water vapor, temperature and radon and their fluxes in an idealized equilibrium boundary layer over land. J Geophys Res 109(D18103)

Collatz GJ, Ball JT, Grivet C, Berry JA (1991) Physiological and environmental regulation of stomatal conductance, photosynthesis and transpiration. Agric Forest Meteorol 54:107-136

Collatz GJ, Ribas-Carbo M, Ball JA (1992) Coupled photosynthesis-stomatal conductance model for leaves of C4 plants. Austr J Plant Physiol 19:519-538

Cox PM, Betts RA, Jones CD, Spall SA, Totterdel IJ (2000) Acceleration of global warming due to carboncycle feedbacks in a coupled climate model. Nature 408:184-187

Goudriaan J, Van Laar HH, Van Keulen H, Louwerse W (1985) Photosynthesis, $\mathrm{CO}_{2}$ and plant production. In: Day W, Atkin RK (Ed) Wheat growth and modeling. NATO ASI Series, Series A, vol 86. Plenum, New York, pp107-122

Goulden ML, Munger JW, Fan S-M, Daube BC, Wofsy SC (1996) Exchange of carbon dioxide by a deciduous forest: Response to interannual climate variability. Science 271:1576-1578

Grammerer K (1989) Respiration of soil and vegetation in grassland. MSc-thesis, University of Nebraska, Lincoln, $119 \mathrm{pp}$

Hadley M (1993) Grasslands for sustainable ecosystems. In: Grasslands for our world. Ed. Baker MJ. SIR, Wellington, New Zealand.

Ham JM, Knapp AK (1998) Fluxes of $\mathrm{CO}_{2}$, water vapor, and energy from a prairie ecosystem during the seasonal transition from carbon sink to carbon source. Agric For Meteorol 89:1-14

Hu S, Chapin III FS, Firestone MK Field CB, Chiariello NR (2001) Nitrogen limitation of microbial decomposition in a grassland under elevated $\mathrm{CO}_{2}$. Nature 409:188-190

Jacobs CMJ, De Bruin HAR (1992) The sensitivity of regional transpiration to land-surface characteristics: Significance of feedback. Climate 5:683-698

Jacobs CMJ (1994) Direct impact of atmospheric $\mathrm{CO}_{2}$ enrichment on regional transpiration. PhD-thesis, Wageningen University, $179 \mathrm{pp}$

Jacobs AFG, Ronda RJ, Holtslag AAM (2003a) Water vapour and carbon dioxide fluxes over bog vegetation. Agric For Meteorol 116:103-112

Jacobs AFG, Heusinkveld BG, Holtslag AAM (2003b) Carbon dioxide and water vapour flux densities over a grassland area in the Netherlands. Int J Climatol 23:1663-1675

Jacobs AFG, Jacobs CM, Heusinkveld BG (2005) $\mathrm{CO}_{2}$ Respiration in a grassland area (submitted)

Jacobs AFG, Heusinkveld BG, Wichink Kruit RJ (2006) Contribution of dew to the water budget of a grassland area in The Netherlands. Water Resour Res 42:WO3415 doi:10.1029/2005WR004055

Jury WA, Gardner WR, Gardner WH (1991) Soil physics, Wiley, New York

Keuning JA (1988) Grashoogtemeter hulpmiddel voor schatting grashoeveelheid. Meststoffen 1:1-3 (in Dutch) 
Kim J, Verma SB (1990) Carbon dioxide exchange in a temperate grassland ecosystem. Bound-Layer Meteorol 52:135-149

Kim J, Verma SB, Clement RJ (1992) Carbon dioxide budget in temperate grassland ecosystem. J Geophysical Res 97:6057-6063

Lloyd J, Taylor JA (1994) On the temperature dependence of soil respiration. Funct Ecol 8:315-323

McMillen RT (1986) A BASIC program for eddy-correlation in non-simple terrain, NOAA Tech. Memo. ERLARL-147, NOAA, Air Resources Lab., Oak Ridge MD

McMillen RT (1988) An eddy-correlation technique with extended applicability to non-simple terrain. Bound-Layer Meteorol 43:231-245

Meyers TP (2001) A comparison of summertime water and CO2 fluxes over rangeland for well watered and drought conditions. Agric For Meteorol 106:205-214

Moore CJ (1986) Frequency response corrections for eddy-correlation systems Bound-Layer Meteorol 37:17-35

Nelson JA, Morgan JA, LeCain DR, Moiser AR, Milchunas DG, Parton BA (2004) Elevated $\mathrm{CO}_{2}$ increases soil moisture and enhances plant water relations in a long-term field study in semi-arid shortgrass steppe of Colorado. Plant Soil 259:169-179

Nemani RR, Keeling CD, Hashimoto H, Jolly WM, Piper SC, Tucker DJ, Myneni RB, Running SW (2003) Climate-driven increases in global terrestrial net primary production from 1982 to 1999. Science 300:1560-1563

Nitschelm JJ, Luscher A, Hartwig UA, Van Kessel C (1997) Using stable isotopes to determine soil carbon input differences under ambient and elevated atmospheric $\mathrm{CO}_{2}$ conditions. Glob Chang Biol 3: $411-416$

Norman JM, Garcia R, Verma SB (1992) Soil surface $\mathrm{CO}_{2}$ fluxes and carbon budget of a grassland. J Geophysical Res 92:18845-18853

Ronda RJ, De Bruin HAR, Holtslag AAM (2001) Representation of the canopy conductance in modelling the surface energy budget for low vegetation. J Appl Meteorol 40:1431-1444

Schnel S (2004) Soil-atmospheric exchange of $\mathrm{CO}_{2}$. MSc-thesis, Department Meteorology and Air Quality, Wageningen University, $54 \mathrm{pp}$

Soegaard H, Jensen NO, Boegh E, Hasager CB, Schelde K, Thomsen A (2003) Carbon dioxide exchange over agricultural landscape using eddy-correlation and footprint modelling. Agric For Meteorol 114:153-173

Suyker AE, Verma SB (2001) Year-round observations of the net ecosystem exchange of carbon dioxide in a native tallgrass prairie. Glob Chang Biol 7:279-290

Valentini R, Matteucci G, Dolman AJ, Schulze E-D, Rebman C, Moors EJ, Granier A, Gross P, Jensen NO, Pilegaard K, Lindroth A, Grelle A, Bernhofer C, Gruenwald T, Aubinet M, Ceulemans R, Kowalski AS, Vesala T, Rannik U, Berbigier P, Loustau D, Gudmundsson J, Thorgeirsson H, Ibrom A, Morgenstern K, Clement R, Moncrieff J, Montagnani L, Minerbi S, Jarvis PG (2000) Respiration as the main determinant of carbon balance in European forests. Nature 404:861-865

Van den Hurk BJJM (1996) Sparse canopy parameterizations for meteorological models. PhD thesis, Department of Meteorology Wageningen University, Wageningen, $271 \mathrm{pp}$

Van Ginkel JH, Whitmore AP, Gorissen A (1999) Lolium perenne grasslands may function as a sink for atmospheric carbon dioxide. J Environ Qual 28:1580-1584

Verma SB, Kim J, Clement RJ (1992) Momentum, water vapor, and carbon dioxide exchange at a centrally located prairie site during FIFE. J Geophysical Res 97:18629-18660

Wang S, Grant RF, Verseghy DL, Black TA (2002) Modelling carbon dynamics of boreal forest ecosystems using the Canadian land surface scheme. Clim Change 55:451-477

Webb EK, Pearman GI, Leuning R (1980) Corrections of flux measurements for density effects due to heat and water vapour transfer. Q J R Meteorol Soc 106:85-100

Wofsy SC, Goulden ML, Munger JW, Fan S-M, Backwin PS, Daube BC, Bassow SL, Bazzaz FA (1993) Net $\mathrm{CO}_{2}$ exchange in a mid-latitude forest. Science 260:1314-1317

Zhang H, Nobel PS (1996) Dependency of $c_{i} / c_{a}$ and leaf transpiration efficiency on the vapour pressure deficit. Aust J Plant Physiol 232:561-568 